\title{
A Relação de Interdependência entre os Processos de Liderança e Motivação: Estudo de Caso de uma Subseção Judiciária do Ceará
}

\author{
Gláucio Ferreira Paz e Fernanda Roda de Souza Araújo Cassundé
}

\begin{abstract}
Resumo: O presente artigo traz uma análise acerca da resposta motivacional dos colaboradores de uma Subseção Judiciária do Ceará a partir do perfil de liderança aplicado nesse ambiente de trabalho. Busca-se analisar os efeitos da liderança sobre a motivação dos indivíduos, além de verificar a correlação entre esses processos. Para tanto, são consideradas importantes teorias que servem de base para a percepção de similaridade das concepções analisadas. Além da pesquisa bibliográfica, é exposto um estudo de caso acerca do tema, por meio de uma pesquisa aplicada aos colaboradores do órgão, permitindo uma análise quantitativa dos resultados. A partir da análise dos dados, observou-se a predominância de uma abordagem de liderança transformacional, na percepção dos envolvidos na pesquisa, além de uma reação motivacional amplamente satisfatória em relação ao aspecto da liderança vivenciado, reforçando a ideia de causa e efeito entre tais conceitos.
\end{abstract}

Palavras-chave: Liderança. Motivação. Colaboradores.

\section{The Relationship of Interdependence between the Processes of Leadership and Motivation: A Case Study of Judicial Subsection in Ceará}

\begin{abstract}
This paper presents an analysis of the motivational response of the employees of a Judicial Subsection in Ceará from the leadership applied in this profile workplace. The aim is to analyze the effects of leadership on the motivation of individuals and to verify the correlation between these processes. For both, are considered important theories that underpin the perception of similarity of concepts analyzed. Besides literature, is exposed a case study on the subject, through a survey applied to employees of the organ, allowing a quantitative analysis of the results. From the data analysis, we observed the predominance of a transformational leadership approach, the perception of those involved in research, in addition to a highly satisfactory reaction in relation to the motivational aspect of experienced leadership, reinforcing the idea of cause and effect between such concepts.
\end{abstract}

Keywords: Leadership. Motivation. Employees.

\section{Introdução}

A liderança é um processo que interfere no nível de motivação dos integrantes da organização. Ao longo do tempo, os perfis de liderança moldam-se à evolução da área de gestão de pessoas, voltando-se para o funcionário, vendo-o como parceiro e corresponsável pelos resultados e pela geração de vantagem competitiva.

\footnotetext{
${ }^{1}$ Graduação em Ciências Contábeis pela Universidade Estadual Vale do Acaraú. Técnico Judiciário - Área Administrativa - Justiça Federal de Primeiro Grau no Ceará. Autor correspondente: glauciopaz@yahoo.com.br;

${ }^{2}$ Graduação em Administração pela Universidade Federal de Pernambuco (2001) e Mestrado em Administração pela Universidade Federal de Pernambuco (2004). Doutoranda em Administração no programa DINTER-UNIVASF/PROPAD. Atualmente é professora Assistente II do colegiado de Administração da Universidade Federal do Vale do São Francisco (UNIVASF) e Pesquisadora de projeto apoiado pelo $\mathrm{CNPq}$ cujo tema refere-se ao desenvolvimento de competências docentes para EAD.
} 
Nesse sentido, Gil (2007) afirma que se observa uma tendência atual de as organizações privadas perceberem os empregados não mais como meros recursos, mas como parceiros e partes integrantes do processo produtivo.

Por outro lado, a Administração Pública se mostra em constante mudança no que concerne às concepções de comportamento organizacional, buscando, até certo ponto, se assemelhar ao setor privado por meio da aplicação de ideias trazidas da iniciativa privada e adequando-as à realidade do setor público.

Além de administrador de recursos e de pessoas, compete ao Gestor Público implementar o perfil de liderança. É necessária, e até mesmo fundamental, a visão dos indivíduos mais como colaboradores do que subordinados, capazes de aderir às políticas e objetivos da organização. Para tanto, o administrador precisa atuar como agente de persuasão, influenciando os liderados por meio de argumentos e induções.

Aliada à abordagem de liderança, temos a motivação como sendo a força que estimula as pessoas a agir (GIL, 2007), decorrente da conjunção de elementos que impulsionam as pessoas à determinada ação. Trata-se de um fator essencial nas relações de trabalho, considerando que está diretamente relacionada aos níveis de desempenho e produtividade.

Trazendo a abordagem motivacional para o âmbito do serviço público, é inegável o grande desafio para o Gestor Público, qual seja, manter os servidores motivados, desenvolvendo suas atividades com presteza e eficiência, uma vez que, ao ser admitido no serviço público, o indivíduo estabelece, em regra, um vínculo duradouro de estabilidade, no qual permanecerá, na maioria das situações, até sua aposentadoria.

Nesse contexto, o Gestor Público, no exercício da função de liderança, deve proporcionar um ambiente no qual o servidor se sinta útil para o processo organizacional. Assim, torna-se necessário conhecer o perfil de cada indivíduo da equipe, reconhecendo seus pontos fortes e fracos, com vistas ao aprimoramento das habilidades funcionais.

A realização deste estudo se justifica pela importância de se manter o servidor público motivado na atividade que desempenha, buscando a eficácia da realização de sua missão. Para tanto, há necessidade de se verificar a repercussão dos tipos de liderança empregados pelo Gestor Público sobre a motivação de sua equipe.

Dentro do campo contextual, este trabalho pretende analisar o nível de motivação e satisfação dos servidores públicos integrantes de uma Subseção Judiciária do Ceará, a partir do perfil de liderança empregado, por meio do estudo e coleta de opinião com base na situação atual. 
Assim, nessa conjuntura, o presente estudo busca responder ao seguinte questionamento: Como a liderança pode influenciar o comportamento motivacional no âmbito de uma Subseção Judiciária do Ceará?

Ademais, objetiva-se identificar a influência da liderança sobre o comportamento motivacional no âmbito de uma Subseção Judiciária do Ceará, verificar as abordagens de liderança aplicadas e, ainda, perceber o nível de motivação para o trabalho dos servidores do órgão em análise.

\section{Discussão Teórica}

\section{Liderança: conceitos e características}

O tema liderança é uma preocupação histórica e foi amplamente estudado sob os mais diversos enfoques. Por vezes, esse conceito foi associado a líderes detentores de dons divinos ou a figuras heroicas, refletindo variadas inferências para diferentes pesquisadores do assunto. Ademais, esse conceito segue despertando o interesse no âmbito do comportamento organizacional e se mostrando indispensável para a compreensão da dinâmica atual das organizações (MACIEL et al., 2008).

Para Robbins (2005), liderança é a capacidade de influenciar um grupo em direção ao alcance de objetivos. O autor ressalta que nem todos os líderes são administradores e nem todos os gestores são líderes, uma vez que o indivíduo pode assumir um papel de liderança apenas em razão do cargo que ocupa, independentemente de suas qualidades.

Loenert (2002) observa como característica da influência da liderança nas organizações, a busca por um relacionamento melhor entre os pares, o incentivo ao trabalho em equipe, a harmonia no grupo e a percepção da importância dos líderes nestes contextos.

De acordo com Alves (2010, p. 49), habilidades e competências são fatores necessários ao ato de liderar:

O exercício da liderança em um ambiente organizacional está inserido em um processo que requer e integra determinadas habilidades e competências do líder. Como habilidade considere-se aquelas peculiaridades inatas que o distinguem como pessoa; e como competência entenda-se as técnicas e os métodos de ação reveladas e desenvolvidas no cotidiano do trabalho. Ambas coexistem no indivíduo de maneira imbricada e somente em certas situações pode-se vislumbrar uma nítida distinção entre elas.

Nesse sentido, Bergamini (1994) enfatiza que a validade da liderança está relacionada à disposição para perceber as necessidades dos colaboradores e dessa forma mantê-los motivados, já que somente quando os lideres são reconhecidos favoravelmente por seus pares é que se abre o caminho para influenciação do comportamento. 
Ainda de acordo com Bergamini (1994, p. 104):

A liderança tem sido também estudada como um processo de interação que envolve trocas sociais. Sob esse aspecto, o líder é visto como alguém que traz um benefício, não só ao grupo em geral, como a cada membro em particular, fazendo nascer desse intercâmbio o valor que seus seguidores lhe atribuem. Em troca, os membros do grupo devolverão ao líder seu reconhecimento e aceitação como forma de lhe conferir a autoridade para dirigir pessoas.

Na mesma linha do presente trabalho, Sobral e Peci $(2008$, p. 216) afirmam que "[...] a liderança envolve pessoas com a disposição para seguir orientações de um líder". Dessa forma, depreende-se que os líderes exercem influências complementares à autoridade formal, o que faz com que as pessoas desenvolvam, de forma comprometida e espontânea, atividades além das designadas. Assim, cabe ao Gestor Público implementar um estilo de liderança que seja capaz de gerar motivação e comprometimento por partes dos colaboradores envolvidos.

\section{Liderança transacional e transformacional: implicações motivacionais}

Dentre as correntes de pesquisa sobre o tema liderança, a abordagem que busca diferenciar a liderança transformacional e a transacional está entre as que mais despertam o interesse dos teóricos (FONSECA et al., 2012 apud AVOLIO et al., 2009).

No estilo transacional aparece a figura do administrador que, em decorrência de seu poder formal, tende a manter o subordinado vinculado ao seu comando. Ocorre, nesse caso, a mera transação em que há, na maioria das vezes, a oferta de benefícios extrínsecos. O poder de influenciação desse tipo de líder é vinculado a sua capacidade de concessão de benefícios ou inflição de punições (BERGAMINI, 1994).

Por outro lado, o líder transformacional detém uma sensibilidade necessária para perceber os desejos de seus seguidores. Há, portanto, um retrato da ação motivacional por meio do relacionamento interpessoal entre líder e liderado (BERGAMINI, 1994).

Bergamini (1994, p. 110) traz um entendimento acerca da liderança transformacional:

A liderança transformacional propõe que a influência ocorra em dupla direção para que se estabeleça o clima de respeito ao outro enquanto pessoa integral. É da convivência com o seguidor que o líder retira a maior fonte de informações de que necessita para o exercício do seu papel; portanto, não somente o influencia como também é influenciado por ele [...].

Nesse sentido, Almeida et al. (2008, p.10) definem liderança transformacional como "[...] uma atuação que amplia e eleva os interesses dos colaboradores, gerando consciência e aceitação da missão e propósitos do grupo e conduzindo os colaboradores a olhar além de seus interesses próprios." 
Por sua vez, Vizeu (2011, p. 58) traz uma distinção entre os modelos:

A primeira consiste no estilo de liderança baseado na capacidade do líder em atender os interesses particulares dos seguidores; já o segundo estilo corresponde à liderança centrada no desenvolvimento dos seguidores, de maneira a permitir que esses adotem um comprometimento com valores coletivos substantivos.

No que concerne à mensuração da liderança transformacional, segundo Mainardes e Domingues (2010, apud BASS, 1985, p. 39), esta se dá por meio de quatro dimensões:

1) Carisma - capacidade de despertar confiança, orgulho e respeito dos seguidores, através da transmissão de um forte senso de missão. É a principal dimensão da liderança transformacional. 2) Inspiração motivacional - compreende a visão do líder e a comunicação desta visão para os seguidores, através de ações motivacionais, que geram altas expectativas, corrigem comportamentos e atitudes, com o objetivo de somar esforços. 3) Estimulação intelectual - proposição de desafios constantes aos seguidores, estimulando sua criatividade para o desenvolvimento de novas idéias e cenários. Esta dimensão incentiva a aprendizagem dos seguidores, para que possam lidar com o desconhecido sem medo. 4) Consideração individualizada - direcionamento de atenção personalizada a cada seguidor, fazendo com que ele sinta-se único e acentuando o relacionamento. Esta dimensão permeia todas as outras e faz com que o líder atue como coach ou mentor.

Inicialmente, depreende-se que, sob todas as circunstâncias, a liderança transformacional é preferível à liderança transacional. No entanto, enquanto Bergamini (1994, p. 109) é enfática ao fazer uma clara diferenciação quando trata desses dois tipos de liderança: "essa diferenciação não deve ser considerada como uma simples sutileza semântica, mas como uma importante separação entre duas filosofias frontalmente discordantes em termos da teoria e da prática administrativa", Fonseca et al., 2012 ressaltam que, inicialmente, se considerava a existência de uma dicotomia entre esses tipos de liderança, contudo, no tempo atual, algumas pesquisas mostram que há uma complementaridade entre os estilos, de forma que a liderança transformacional suplementa a transacional.

Nesse contexto, do ponto de vista motivacional, não há controvérsias acerca da efetividade do líder do perfil transformacional frente ao transacional, considerando que o primeiro agrega maior lealdade, comprometimento e satisfação dos liderados.

\section{Motivação: definições e reflexo no serviço público}

A motivação, assim como a liderança, é parte integrante do processo organizacional. Representa uma condição imprescindível para o alcance dos objetivos almejados pela organização. Ainda é possível definir como uma força que impulsiona o indivíduo a um determinado objetivo.

Para Chiavenato (2008, p. 231), a motivação se traduz na relação entre o que há no íntimo do indivíduo e suas necessidades: 
A motivação existe dentro das pessoas e se dinamiza com as necessidades humanas. Todas as pessoas têm suas necessidades próprias, que podem ser chamadas de desejos, aspirações, objetivos individuais ou motivos. As necessidades humanas ou motivos são forças internas que impulsionam e influenciam cada pessoa determinando seus pensamentos e direcionando o seu comportamento diante das diversas situações da vida.

Nesse sentido, segundo Gil (2007) o comportamento humano é motivado pelo desejo de atingir algum objetivo e os motivos são as molas da ação, é o que impulsiona e mantém o comportamento dos indivíduos. Assim, os motivos dirigem para os objetivos que estão fora do indivíduo.

De acordo com Robbins (2005, p. 132) é possível definir motivação como o "processo responsável pela intensidade, direção e persistência dos esforços de uma pessoa para o alcance de uma determinada meta". Na mesma linha, Maximiano (2000), afirma que, por meio da motivação, o desempenho do indivíduo é impulsionado por certos motivos.

Sobral e Peci (2008, p. 207) conceituam motivação como "a predisposição individual para exercer esforços que busquem o alcance de metas organizacionais, condicionada pela capacidade de esses esforços satisfazerem, simultaneamente, alguma necessidade individual". Assim, o desafio do gestor consiste em direcionar os esforços individuais para o êxito organizacional, da mesma forma que busca a melhoria do desempenho dos indivíduos no cargo.

Lobos (1975, p. 18) traz um apanhado do conceito de motivação:

Em resumo, o conceito da "motivação" pode ser sintetizado nos seguintes termos: a) está orientada para a consecução de um objetivo; b) está constituída por todos os fatores que incitam e dirigem o comportamento de um indivíduo, isto é, a "motivação" refere-se à maneira como a conduta se inicia, recebe energia, é freada, etc., e à classe de reação subjetiva que apresenta o organismo, enquanto tudo isso acontece.

O indivíduo motivado demonstra maior comprometimento com a organização que integra, gerando sinergia motivacional. Além disso, os fatores que determinam a motivação estão relacionados à eficácia das instituições. Dessa forma, a partir da compreensão do processo motivacional que rege seus colaboradores advém a conveniência de as organizações ingerirem-se no processo de gestão de pessoas, alinhando os desempenhos individuais aos objetivos organizacionais.

No caso particular do serviço público, alguns aspectos próprios tendem a diferenciar a influenciação da motivação e o comportamento dos indivíduos em relação ao que se percebe no setor privado (RODRIGUES et al., 2014). Assim, a motivação nesse contexto não se mostra como uma das tarefas mais fáceis para quem está no comando da organização. As características e aspectos do cargo público contribuem para a acomodação do agente público, dificultando a manutenção do 
comportamento motivacional, considerando que, em regra, o desempenho não dita a permanência ou afastamento do cargo.

Dessa forma, percebe-se que é necessário estudar meios de motivação que possam ser aplicados ao regime público. Nesse sentido, Rodrigues et al. (2014) asseveram que a reflexão sobre a importância do papel de servir ao bem público é vista por diversos autores como o mais significativo fator de motivação dos servidores públicos para o trabalho.

\section{Liderança e motivação: uma relação de causa e efeito}

Durante um longo espaço de tempo, os indivíduos foram considerados apenas como um dos recursos necessários para o desempenho das atividades de uma organização, o que os assemelhava às máquinas, sob esse aspecto. Contudo, a evolução do pensamento e das teorias sobre o assunto, fez com que essa concepção passasse por modificações no decorrer do tempo. As mudanças ocorridas deixam de lado a figura das pessoas como meros recursos e geram uma maior preocupação com o indivíduo, já que ele passa a ser considerado ativo intangível, capital da organização, devendo, dessa forma, ser gerido.

A evolução do ponto de vista acerca da influência das pessoas interferiu nos processos comportamentais de liderança e motivação, os quais estão diretamente relacionados. Percebeu-se que lidar com pessoas na organização não é algo de simples condução, uma vez que os aspectos humanos são difíceis de compreender e, por consequência, administrar. Assim, o entendimento do comportamento organizacional se torna imprescindível para que os gestores possam diminuir as incertezas na gestão da equipe.

O administrador deve entender por qual razão os colaboradores respondem a determinados estímulos e não a outros, o que os motiva, por que se envolvem em certos comportamentos e desprezam outros e principalmente qual o estilo de liderança mais adequado em situações específicas (SOBRAL e PECI, 2008).

Nesse sentido, Loenert (2002, p. 3) destaca a essencialidade do reforço positivo adotado pelo líder que busca uma resposta desimpedida e favorável da equipe:

Como função de líder de equipe é preciso trabalhar no sentido de construir o senso de compromisso e confiança de cada participante e da equipe como um todo. Existe uma diferença importante entre senso de compromisso, responsabilidade individual e senso de responsabilidade mútua. O líder deve procurar dar a sua equipe e aos indivíduos um reforço positivo e construtivo, evitando as intimidações. No contexto organizacional é fácil coagir as pessoas, porém com o decorrer do tempo, este tipo de liderança torna-se saturada, fazendo com que as pessoas percam o entusiasmo e a iniciativa. O reforço positivo e construtivo impulsiona o senso de responsabilidade e confiança mútua, essencial para a performance da equipe. 
Percebe-se que a liderança, assim como a motivação, reside no meio subjetivo das pessoas. Assim sendo, infere-se que o limite do desempenho é dinâmico e se adapta de acordo com as atitudes e se altera com a aquisição de novos conhecimentos e habilidades e com o que é sentido no ambiente de trabalho. Essa constante adaptação permite que os colaboradores desenvolvam competências que podem ser aproveitadas no campo organizacional.

Segundo Sobral e Peci (2008), a motivação resulta do alinhamento dos objetivos individuais com os organizacionais e é uma das mais intrincadas tarefas de um gestor.

[...] No entanto, mesmo com todas as técnicas e teorias a seu dispor, nem todos os administradores obtêm os mesmos resultados na motivação de seus subordinados. Isso acontece porque alguns deles não são lideres eficazes. A liderança é um dos papéis do administrador que está intimamente relacionada com a direção e a motivação dos membros organizacionais (SOBRAL e PECI, 2008, p. 216).

Bergamini (1994, p. 105) defende que há uma inevitável união entre a dinâmica motivacional e a eficácia da liderança, coadunando-se com a linha de pesquisa do presente trabalho: "Esses dois termos, a partir de um determinado momento, parecem definitivamente unidos na teoria e na prática por uma relação de causa e efeito".

Desse modo, ainda de acordo com Bergamini (1994, p. 106), reforça-se a percepção da existência de um elo entre os construtos em análise, "considerando liderança e motivação como dois assuntos tão entrelaçados, é possível concluir que guardam uma ligação de parentesco forte entre si, a ponto de serem considerados como sinônimos".

\section{Método}

Demonstra-se, nesta seção, o procedimento metodológico que norteia esta pesquisa. Descrevese o método de abordagem, ou seja, o tipo de pesquisa utilizado e os elementos empregados em sua realização, além de definir o universo, o instrumento de coleta de dados e a forma como se desenvolve a análise dos dados.

Em relação ao tipo de pesquisa, quanto aos fins optou-se pelo estudo exploratório, haja vista a diminuta produção de pesquisa que envolve os servidores públicos do órgão objeto de análise. A pesquisa exploratória é apropriada nos casos em que há poucos estudos sobre a população em análise e, assim, a formação de uma concepção surge basicamente a partir das ideias dos participantes.

(CRESWELL, 2007) 
Quanto aos meios, tem-se a pesquisa bibliográfica, por meio da exploração dos temas de liderança e motivação e da demonstração da relação de interdependência desses construtos, e o estudo de caso. Esse último método abrange uma "descrição detalhada do cenário e das pessoas, seguida por análise de dados para temas ou questões". (CRESWELL, 2007, p. 195)

O universo compreendeu 52 (cinquenta e dois) servidores estatutários detentores de cargo efetivo distribuídos em 3 (três) Varas Federais que compõem a Subseção Judiciária em estudo e que são denominadas, neste trabalho para fins de análise, de Unidade I, Unidade II e Unidade III. Ao final da pesquisa, excluindo-se o autor e um servidor em gozo de licença, obteve-se um total de 50 questionários respondidos, equivalente a 96,15\% do universo.

Concernentemente ao instrumento utilizado para a coleta de dados, tem-se o questionário objetivo aplicado com servidores. Optou-se por trabalhar com esse instrumental de coleta de dados por ele possibilitar uma análise das informações, podendo o pesquisador concordar, discordar e levantar suas concepções acerca dos dados coletados.

A primeira parte do questionário visou identificar o perfil dos servidores, considerando os critérios: sexo, idade, grau de escolaridade e tempo de serviço na instituição. A segunda parte o questionário foi aplicada para identificar a resposta motivacional, na percepção dos servidores, a partir de alguns fatores, sob a mensuração dos seguintes valores: "Concordo", "Concordo parcialmente", "Indiferente", "Discordo" e "Discordo parcialmente". Por fim, na terceira parte do questionário, por meio de uma questão mista, buscou-se verificar a abordagem de liderança vivenciada em cada unidade.

Quanto aos procedimentos para análise de dados, tem-se o enfoque quantitativo, por meio de um levantamento de dados que, em seguida, foram analisados numericamente. Segundo Richardson (1985) o método quantitativo emprega a quantificação tanto na coleta de dados quanto no tratamento das informações por meio de técnicas estatísticas.

Os dados foram analisados a partir das afirmativas do questionário. Cada afirmativa gerou uma resposta que foi analisada em termos percentuais para possibilitar uma leitura da percepção dos servidores, a partir da interpretação dos dados coletados e identificação do nível de motivação do servidor e a relação desse processo com o perfil de liderança adotado.

\section{Análise de Dados}

Inicialmente são expostos os resultados da pesquisa no que diz respeito ao perfil dos servidores, tendo como critérios: sexo, idade, grau de escolaridade e tempo de serviço na instituição. 
Dos 50 servidores respondentes, $54 \%$ são do sexo masculino, ao passo que 46 são do sexo feminino.

Quanto à idade dos servidores, apenas $4 \%$ têm menos de 25 anos, a maioria (72\%) entre 25 e 35 anos, $20 \%$ entre 36 e 45 anos e o restante (4\%) acima de 45 anos.

No que se refere ao grau de instrução, a maior parte dos pesquisados (60\%) possui especialização, $26 \%$ superior completo, $12 \%$ superior incompleto e apenas $2 \%$ nível médio. Constatou-se, ainda, que nenhum servidor cursou mestrado ou doutorado.

Por fim, em relação ao tempo de serviço, relevante critério de observação, considerando que nos primeiros anos de serviço, fatores como estágio probatório e a consequente busca pela estabilidade podem interferir, ainda que indiretamente, na resposta motivacional, verificou-se que $22 \%$ dos colaboradores têm menos de 1 ano de serviço, 22\% trabalham de 1 a 2 anos, $30 \%$ de 3 a 5 anos, 18\% de 6 a 10 anos e, por fim, $8 \%$ acima de 10 anos.

No que concerne ao levantamento de dados quanto ao nível de motivação e aos fatores motivacionais, na percepção dos servidores, a tabela 1 concentra os dados percentuais resultantes das questões objetivas do questionário.

Tabela 1: Análise da percepção dos servidores a partir de fatores motivacionais

\begin{tabular}{lllll}
\hline Proposições & Concordo & $\begin{array}{l}\text { Concordo } \\
\text { parcialmente }\end{array}$ & Discordo & $\begin{array}{l}\text { Discordo } \\
\text { parcialmente }\end{array}$ \\
\hline Plano de carreira / benefícios & $10 \%$ & $44 \%$ & $26 \%$ & $20 \%$ \\
Realização profissional & $42 \%$ & $52 \%$ & $6 \%$ & $0 \%$ \\
Papel do servidor no bem comum & $86 \%$ & $12 \%$ & $0 \%$ & $2 \%$ \\
Autonomia / Expressar opinião & $72 \%$ & $28 \%$ & $0 \%$ & $0 \%$ \\
Reconhecimento no trabalho & $62 \%$ & $36 \%$ & $2 \%$ & $0 \%$ \\
Comunicação - Gestor servidor & $74 \%$ & $22 \%$ & $2 \%$ & $2 \%$ \\
Relacionamento interpessoal & $78 \%$ & $22 \%$ & $0 \%$ & $0 \%$ \\
\hline
\end{tabular}

Fonte: Elaborado pelo autor com dados da pesquisa

É relevante ressaltar, para melhor compreensão, que cada Vara Federal tem uma liderança própria, dessa forma, analisa-se a Subseção de forma ampla, notadamente, em relação à resposta motivacional de todos os servidores de acordo com os critérios que são apresentados. Em seguida, avalia-se paralelamente cada unidade no que se refere especificamente à abordagem de liderança.

A primeira análise da resposta motivacional reside na proposição: $O$ atual plano de carreira $e$ a política de benefícios proporcionam motivação para o trabalho. Esse foi o fator que obteve a 
avaliação menos favorável dentre os demais, em que apenas $10 \%$ dos respondentes concordaram plenamente que esse elemento gera motivação, seguidos de $44 \%$ que concordaram em parte e de $26 \%$ e $20 \%$ que discordaram totalmente e em parte, respectivamente. Percebe-se que há um razoável descontentamento nesse importante quesito que abrange um contexto macro a ponto de fugir do arcabouço da gestão local, haja vista que a política de benefícios é aplicada a todos os servidores da carreira e não apenas aos integrantes do órgão em estudo. Apesar de as lideranças analisadas não possuírem ingerência sobre esse aspecto, houve a necessidade de verificação desse ponto por se tratar um fator relevante que reflete sobre diversas variáveis, como qualidade de vida no trabalho, remuneração, campo motivacional, entre outras, e está presente em a toda a atividade profissional do servidor.

Já em relação à afirmativa: Realizo-me profissionalmente com o trabalho que executo, tem-se uma melhor percepção dos respondentes sobre esse ponto quando comparada com a análise anterior. Nessa observação, a maior parte disse que concorda em parte (52\%) e totalmente (42\%), enquanto apenas 6\% discordaram. Observa-se que os servidores, de forma geral, encontram-se satisfeitos com a atividade que desempenham. Eis um valor determinante para permanência do colaborador no cargo que ocupa e um indispensável elemento de manutenção da motivação para o trabalho, além de ser uma inegável consequência da influência exercida pela liderança.

Quanto ao item: $O$ papel do servidor público na realização do bem comum representa um relevante fator de motivação, tem-se a categoria que apresentou melhor avaliação, com a concordância total de $86 \%$ dos questionados, seguidos de $12 \%$ que concordaram parcialmente e de $2 \%$ que discordaram parcialmente. Constata-se que os colaborarem envolvidos na pesquisa tem um entendimento semelhante ao de muitos autores que veem a missão do serviço público como o mais significativo indicador motivacional quando se fala em instituições do setor público. Esse fator envolve o sentimento de orgulho pela pertença ao serviço desempenhado e a percepção da importância do papel do servidor na sociedade.

Concernentemente à proposição: Tenho autonomia para propor melhorias na execução do meu trabalho e expressar opiniões contrárias às de meu superior imediato, quando for necessário, no que diz respeito aos trabalhos na minha área, a maioria dos servidores pesquisados manifestou-se positivamente acerca dessa questão, considerando que $72 \%$ concordaram totalmente e $28 \%$ concordaram em parte. Esse é o primeiro item analisado, em que se percebe uma intervenção direta da liderança sobre a percepção dos servidores. Pode-se afirmar que essa notável aceitação é produto de uma gestão com traços de flexibilidade, que sabe ouvir e que valoriza os membros da equipe, o que aumenta o desempenho e o interesse de contribuir com a instituição.

No que se refere ao quesito: Sinto-me reconhecido pelo trabalho que executo, dentre os servidores que responderam o questionário, $62 \%$ concordaram plenamente com a afirmativa, seguidos 
de $36 \%$ que concordaram em parte e $2 \%$ que discordaram totalmente. Essa percepção retrata um elevado grau de satisfação dos respondentes em relação à influência exercida pelos líderes. Trata-se de um elemento primordial para a formação e renovação da motivação para o trabalho, uma vez que no reconhecimento há um retorno do esforço empenhado na realização das tarefas e serve como força impulsionadora para o crescimento profissional.

No que diz respeito à assertiva: A comunicação entre os gestores e servidores é adequada e constitui fator motivacional, a maior parte dos pesquisados (74\%) concordaram totalmente e parcialmente $(22 \%)$, ao passo que apenas $2 \%$ discordaram plenamente, seguindos de $2 \%$ que discordaram parcialmente. Percebe-se que os servidores questionados consideram que há uma comunicação favorável no ambiente de trabalho, além compreendê-la como elemento de motivação. Informar os colaboradores com clareza e objetividade, de modo a assegurar que a mensagem seja entendida, utilizar-se de feedback quando necessário e orientar a equipe são condutas que, ao serem adotadas pelo líder, são capazes de gerar envolvimento e motivação.

Por fim, em resposta ao tema: $O$ relacionamento interpessoal entre os gestores $e$ colaboradores reflete no nível de motivação para o trabalho, a grande maioria dos envolvidos na pesquisa concordou plenamente (78\%) e $22 \%$ concordaram em parte, o que demonstra que as ligações profissionais no local estudado tendem a criar um ambiente propício ao fortalecimento de um clima organizacional harmônico, em que haja empatia e estabilidade nas relações de trabalho.

Sob outro ponto da pesquisa, com o objetivo de definir a abordagem de liderança aplicada em cada unidade que compõe o órgão em estudo, buscou-se analisar como os servidores percebem a liderança no que diz respeito a sua característica preponderante. Para tanto, foi solicitado que respondessem a pergunta: Qual a palavralexpressão que melhor retrata o atual perfil de liderança? A tabela 2 traz as informações levantadas.

Tabela 2: Características de liderança

\begin{tabular}{l|lll}
\hline Respostas & Unidade I & Unidade II & Unidade III \\
\hline Coação e intimidação & $0 \%$ & $0 \%$ & $0 \%$ \\
$\begin{array}{l}\text { Empatia e Flexibilidade } \\
\text { Influenciação por meio de recompensas e trocas }\end{array}$ & $58,82 \%$ & $31,25 \%$ & $11,76 \%$ \\
$\begin{array}{l}\text { condicionadas ao desempenho } \\
\text { Relação interpessoal favorável e percepção das } \\
\text { necessidades dos colaboradores }\end{array}$ & $41,18 \%$ & $25 \%$ & $5,88 \%$ \\
\hline
\end{tabular}

Fonte: Elaborado pelo autor com dados da pesquisa 
Observa-se que a liderança da Unidade I foi vista por seus integrantes como uma gestão que se baseia essencialmente na flexibilidade $(58,82)$ e que se sensibiliza com as necessidades dos colaboradores $(41,18 \%)$. Enquanto que na Unidade II levantou-se a característica de influenciação por meio de transação de benefícios extrínsecos, na opinião de $25 \%$ dos servidores que compõem essa unidade, embora prevaleçam, na avaliação dos demais, os traços positivos de empatia e flexibilidade $(31,25 \%)$ e relação interpessoal favorável $(43,75 \%)$. Por último, na Unidade III, tem-se uma percepção que converge para o aspecto de liderança que mantém uma relação de dupla direção e busca conhecer as necessidades dos integrantes da equipe (82,36\%), seguida de $11,76 \%$ que viram como principal característica da liderança a empatia e flexibilidade e apenas 5,88\% tiveram uma impressão menos favorável acerca da gestão dessa unidade, optando pelo traço de liderança que influencia por meio de recompensas.

Verificou-se, em geral, que nas três unidades há uma percepção favorável em relação à gestão e a predominância de uma abordagem de liderança transformacional, na visão dos colaboradores envolvidos. Nesse tipo de abordagem há uma preocupação do líder para com o liderado e o convencimento desse por meio do envolvimento e estímulo, o que torna o ambiente de trabalho mais propício à motivação, quando comparada com a visão transacional, que se baseia apenas em recompensas dependentes do desempenho.

\section{Conclusões}

Os temas abordados neste trabalho remetem a uma constante análise e discussão tanto para os líderes como para os liderados. Desde a percepção de que as pessoas não são meros recursos, mas parceiras da organização no alcance de seus objetivos e geração de valor, houve a necessidade de as instituições, sejam públicas ou privadas, buscarem construir um ambiente favorável ao trabalho, em que os indivíduos se sintam satisfeitos e motivados para a execução de seu papel.

O exercício da liderança está estritamente relacionado à atividade de motivação das pessoas, assim, no processo de influenciação deve haver o equilíbrio entre o que o liderado espera e o comportamento do líder.

Os resultados demonstram que os envolvidos na pesquisa se mostram motivados diante de todos os fatores abordados, desde os aspectos em que não uma interferência real da liderança, até naqueles que o líder tem influência direta sobre a percepção do servidor. Destaca-se que a relação interpessoal favorável entre gestores e colaboradores é apontada tanto como fator motivacional, quanto como característica da liderança vivenciada em todas as unidades. 
Percebe-se que a abordagem de liderança percebida pelos servidores reúne características que convergem para o estilo transformacional de liderar. Nessa abordagem há uma relação de estímulo mútuo entre líder e liderado, o que faz com que o gestor conheça as necessidades dos colaboradores e possa interferir de forma mais oportuna na motivação.

Aliada à visão positiva dos colaboradores em relação aos gestores, têm-se um elevado nível de satisfação e motivação. Esse resultado retrata a ideia ressaltada por importantes teorias, no sentido de que os aspectos de liderança e motivação consubstanciam uma relação de causa e efeito, considerados por alguns autores inclusive como sinônimos.

A relação entre os processos de liderança e motivação declara que o líder sempre é um instrumento do grupo. A compreensão dos estímulos que motivam os liderados explica o processo social da liderança e também possibilita o desenvolvimento dos líderes (MAXIMIANO, 2004). Assim, é incontestável a importância do líder no desenvolvimento da força motivacional de seus liderados.

\section{Referências}

ALMEIDA, M. I. R.; NOVAES, M. B. C.; YAMAGUTI, C. L. Liderança e gestão estratégica de pessoas: duas faces da mesma moeda. Revista de Administração da UFSM, v. 1, n. 1, art. 1, p. 7-25, 2008.

ALVES, S. Liderança organizacional: discussão sobre um conceito-chave à administração. Revista Pensamento Contemporâneo em Administração, v. 4, n. 1, p. 43-53, 2010.

BERGAMINI, C. W. Liderança: administração do sentido. Revista de Administração de Empresas, v. 34, n. 3, p. $102-114,1994$.

CHIAVENATO, I. Administração Geral e Pública. 2. ed. Rio de Janeiro: Elsevier, 2008.

CRESWELL, J. W. Projeto de pesquisa: métodos qualitativo, quantitativo e misto. 2 ed. Porto Alegre: Artmed, 2007.

FONSECA, A. M. O.; PORTO, J. B.; BARROSO, A. C. O efeito de valores pessoais nas atitudes perante estilos de liderança. Revista de Administração Mackenzie, v. 13, n. 3, p. 122-149, 2012.

GIL, A. C. Gestão de Pessoas: enfoque nos papéis profissionais. 1. ed. 7a reimpr. São Paulo: Atlas, 2007.

LOBOS, J. Teorias sobre a motivação no trabalho. Revista de Administração de Empresas, v. 15, n. 2 , p. 17-25, 1975.

LOENERT, M. A. Motivação e liderança: um trabalho em equipe nas organizações. Revista Eletrônica de Ciência Administrativa, v. 1, n. 2, p. 0-0, 2002. 
MACIEL, C. O.; HOCAYEN-DA-SILVA, A. J.; CASTRO, M. Liderança e cooperação nas organizações. Revista de Economia e Administração, v. 7, n. 3, p. 313-327, 2008.

MAXIMIANO, A. C. A. Introdução à Administração. 5. ed. São Paulo: Atlas, 2000. Atlas, 2004.

Teoria Geral da Administração: da revolução urbana à revolução digital. 4. ed. São Paulo:

MAINARDES, E. W.; DOMINGUES, M. J. Estilos de liderança: estudo de caso em uma organização militar. Revista de Administração da Unimep, v. 8, n. 2, p. 35-50, 2010.

RICHARDSON, R. J. et al. Pesquisa Social: métodos e técnicas. São Paulo: Atlas, 1985.

ROBBINS, S. P. Comportamento Organizacional. 11. ed. São Paulo: Pearson Prentice-Hall, 2005.

RODRIGUES, W. A.; REIS NETO, M. T.; GONÇALVES FILHO, C. As influências na motivação para o trabalho em ambientes com metas e recompensas: um estudo no setor público. Revista de Administração Pública, v. 48, n. 1, p. 253-273, 2014.

SOBRAL, F.; PECI, A. Administração: Teoria e Pratica no Contexto Brasileiro. 1. ed. São Paulo: Pearson Prentice-Hall, 2008.

VIZEU, F. Uma aproximação entre Liderança Transformacional e Teoria da Ação Comunicativa. Revista de Administração Mackenzie, v. 12, n. 1, art. 213, p. 53-81, 2011.

\section{Como citar este artigo (Formato ABNT):}

PAZ, G.F. e CASSUNDÉ, F.R.S.A. a relação de interdepend encia entre os processos de liderança e motivação: Estudo de uma subsessão judiciária do ceará. Id on Line Revista de Psicologia, Novembro de 2014, vol.8, n.24, p. 137-151. ISSN 1981-1189. 